\title{
Benzilaminopurina e giberelina no processo germinativo do araçazeiro amarelo
}

\author{
Benzylaminopurine and gibereline in the germinate process of yellow araça \\ Bencilaminopurina y giberelina en el processo de la germinacion del araza amarillo
}

Thomas Gustavo Rau

ORCID: https://orcid.org/0000-0002-6651-4317

Universidade Tecnológica Federal do Paraná, Brasil

E-mail: thomas_g.rau @ hotmail.com

Juliana Cristina Radaelli

ORCID: https://orcid.org/0000-0002-8391-1795

Universidade Tecnológica Federal do Paraná, Brasil

E-mail: julianaradaelli@gmail.com

Américo Wagner Júnior

ORCID: https://orcid.org/0000-0001-5081-5281

Universidade Tecnológica Federal do Paraná, Brasil

E-mail: americowagner@utfpr.edu.br

Idemir Citadin

ORCID: https://orcid.org/0000-0001-9416-2761 Universidade Tecnológica Federal do Paraná, Brasil

E-mail: idemir.citadin@gmail.com

Gisely Correa de Moura

ORCID: https://orcid.org/ 0000-0002-1189-7242 Universidade Tecnológica Federal do Paraná, Brasil

E-mail: correa.gisely@gmail.com

Sérgio Miguel Mazaro

ORCID: https://orcid.org/0000-0003-2787-9409

Universidade Tecnológica Federal do Paraná, Brasil

E-mail: sergio@utfpr.edu.br

\begin{abstract}
Resumo
Devido ao grande potencial econômico do araçazeiro amarelo como fornecedor de alimento saudável e com possíveis usos farmacêuticos, o estudo de meios de reprodução da espécie se torna de interesse para sua difusão em cultivos. O objetivo deste trabalho foi avaliar o efeito da giberelina e da benzilaminopurina no processo germinativo do araçazeiro. O estudo foi realizado na Universidade Tecnológica Federal do Paraná - Câmpus Dois Vizinhos, com sementes de araçá amarelo. Foi utilizado delineamento inteiramente casualizado, em fatorial $2 \times 3$ (hormônio x concentração), com quatro repetições de 100 sementes. Os hormônios usados foram 6-benzilaminopurina (BAP) e ácido giberélico $\left(\mathrm{GA}_{3}\right)$ nas concentrações de 0,50 e $100 \mathrm{mg} \mathrm{L}^{-1}$. Também se avaliou o efeito do armazenamento destas por 20 dias em geladeira, sendo considerado o tratamento testemunha. O experimento foi conduzido no Laboratório de Fisiologia Vegetal com sementes postas para germinar em caixas gerbox em câmara B.O.D. Foram avaliados a porcentagem, índice de velocidade e tempo médio de germinação. Para o araçá amarelo Ya-cy não é necessário o uso de benzilaminopurina para alterar os processos germinativos. Recomenda-se o uso de $50 \mathrm{mg} \mathrm{L}^{-1} \mathrm{de}$ giberelinas ou estratificação a frio para obter melhores respostas germinativas.
\end{abstract}

Palavras-chave: Hormônios; Psidium cattleyanum Sabine; Dormência; Germinação.

\begin{abstract}
Due to the great economic potential of the yellow cherry guava as a supplier of healthy food and possible pharmaceutical uses, the study of means of reproduction of the species becomes of interest for its diffusion in crops. The objective of this work was to evaluate the effect of gibberellin and benzylaminopurine on the germination process of yellow cherry guava, Ya-cy variety. The study was carried out at the Universidade Tecnológica Federal do Paraná Dois Vizinhos, with yellow cherry guava seeds, Ya-cy variety. The experimental design was completely randomized, in factorial $2 \times 3$ (hormone $\times$ concentration), with four replicates of 100 seeds. The hormones used were 6benzylaminopurine (BAP) and gibberellic acid $\left(\mathrm{GA}_{3}\right)$ at concentrations of 0,50 and $100 \mathrm{mg} \mathrm{L}^{-1}$. It was also evaluated the effect of the storage of these for 20 days in refrigerator, being considered the control treatment. The experiment was conducted in the Laboratory of Plant Physiology with seeds placed to germinate in gerbox boxes in chamber B.O.D. The percentage, speed index and average germination time were evaluated. For the yellow cherry guava Ya-cy it is not necessary to use benzylaminopurine to alter the germinative processes. It is recommended to use $50 \mathrm{mg} \mathrm{L}^{-1}$ of gibberellins or cold stratification for better germinative responses.
\end{abstract}

Keywords: Hormones; Psidium cattleyanum Sabine, Dormancy; Germination. 


\section{Resumen}

Debido al gran potencial económico del arazá amarillo como proveedor de alimentos saludables y con posibles usos farmacéuticos, el estudio de los medios de reproducción de la especie se vuelve de interés para su difusión en los cultivos. El objetivo de este trabajo fue evaluar el efecto de la giberelina y la bencilaminopurina en el proceso germinativo del arazá amarillo variedad Ya-cy. El estudio se realizó en la Universidad Tecnológica Federal de Paraná - Câmpus Dois Vizinhos, con semillas de arazá amarillas. Se utilizó un diseño completamente al azar, en factorial 2 x 3 (tipo de la hormona x concentración), con cuatro repeticiones de 100 semillas. Las hormonas utilizadas fueron 6bencilaminopurina (BAP) y ácido giberélico $\left(\mathrm{GA}_{3}\right)$ en concentraciones de 0,50 y $100 \mathrm{mg} \mathrm{L}{ }^{-1}$. También se evaluó el efecto de almacenar estos durante 20 días en nevera, considerando el tratamiento control. El experimento se llevó a cabo en el Laboratorio de Fisiología Vegetal con semillas preparadas para germinar en gerboxes en un B.O.D. Se evaluó el porcentaje, índice de velocidad y tiempo promedio de germinación. Las semilla del arazá amarillo, variedad Ya-cy no requiere el uso de bencilaminopurina para alterar los procesos de germinación. Se recomienda utilizar $50 \mathrm{mg}$ $\mathrm{L}^{-1}$ de giberelinas o estratificación en frío para obtener mejores respuestas germinativas.

Palabras clave: Hormonas; Psidium cattleyanum Sabine, Dormancia; Germinación.

\section{Introdução}

A espécie Psidium cattleyanum Sabine, popularmente conhecida por araçá amarelo ou araçá do campo é fruteira nativa encontrada desde o Estado do Ceará até o Rio Grande do Sul (Lorenzi et al, 2006), cujas flores brancas são melíferas, o que a torna atraente para pequena propriedade rural. Além disso, a maturação dos frutos ocorre entre os meses de janeiro e fevereiro em espécies presentes no Bioma Floresta com Araucárias (Danner et al., 2010) época de menor disponibilidade de frutos no mercado, além de permitir mais de uma safra por ciclo produtivo.

Os frutos também apresentam potencial econômico especialmente por sua polpa de odor agradável e sabor exótico, doce-ácido, que o torna de grande aceitação pelo mercado consumidor (Franzon et al, 2009; Lorenzi, 2008), além de serem ricas em vitaminas, sais minerais e apresentarem baixos teores de açúcar (Fetter et al, 2010).

A elevada concentração de compostos fenólicos é outro aspecto que chama a atenção nesta fruta, podendo ser utilizados para uso farmacêutico por sua ação antimicrobiana e antioxidante (Medina, 2009) e pelos elevados teores de ácido ascórbico que podem atingir níveis de 4 a 7 vezes superiores às frutas cítricas (Giacobbo et al., 2008; Manica, 2000), com

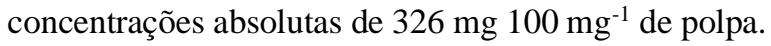

O araçá além de poder ser consumido in natura apresenta maior potencialidade na forma de processados, como sucos, geleias, licores e doces, os quais podem manter suas qualidades sensoriais por maior tempo, já que o fruto apresenta curto período de prateleira (Santos et al., 2007). Apesar destas características, essa fruteira ainda é pouco explorada. Para contornar essa situação, principalmente dentro da agricultura familiar, torna-se importante a implantação de pomares comerciais, preferencialmente com uso de cultivares já lançadas pelos programas de melhoramento, como o araçazeiro amarelo Ya-Cy, cuja vantagem é a possibilidade de ocorrência de três colheitas dentro do mesmo ciclo produtivo (Zanela et al., 2012), ser produtora de frutos com qualidades sensoriais superiores, fato que a tornaram cultivar comercial.

Para a obtenção de mudas desta fruteira, a propagação vegetativa tem apresentado resultados com pouca eficiência (Nachtigal e Fachinello, 1995). Com esta dificuldade, ganha importância a obtenção de mudas utilizando-se sementes. Apesar deste método de propagação ser evitado pela maioria das fruteiras pela variabilidade genética que ocorre nas progênies, no caso do araçazeiro esse efeito é reduzido, pois a formação da semente é considerada facultativamente de maneira apomítica, gerando descendência semelhante entre si e com a planta genitora (Franzon et al., 2009).

Contudo, as sementes de araçazeiro amarelo podem apresentar o fenômeno de dormência, prejudicando os processos metabólicos, necessários para rápida germinação. Zamith e Scarano (2004) descreveram que a espécie apresenta tempo médio de germinação de 32,2 dias, sendo considerada germinação lenta, quando comparada a outras 44 espécies analisadas por estes autores.

Segundo Fowler e Bianchetti, (2000) a dormência se torna empecilho em plantios por desuniformisar, atrasar e até impedir a germinação. De acordo com Zanela el al., (2012), as sementes de araçá amarelo apresentam dormência fisiológica, 
necessitando-se segundo Trevisan et al. (2004) de curto período de estratificação à frio.

A quebra da dormência fisiológica por meio do uso de estratificação pode estar associada ao aumento do balanço entre os fitormônios giberelinas e ácido abscísico, já que o primeiro pode estar envolvido com o processo de ativação do crescimento vegetativo do embrião, mobilização das reservas energéticas encontradas no endosperma ou ao enfraquecimento do tegumento, permitindo o desenvolvimento do embrião e o segundo impedindo a germinação (Taiz et al., 2017). Além disso, alguns autores como Khan (1994) e Marcos Filho (2005), descrevem a necessidade do uso de citocininas para bloquear ou enfraquecer o efeito do ácido abscísico.

Contudo, para maior esclarecimento do papel destes hormônios e do frio sobre a semente de araçazeiro amarelo, fazse necessário estudá-los. Este estudo teve por objetivo avaliar o efeito da aplicação exógena de giberelinas e de citocininas, bem como, da estratificação a frio no processo germinativo de sementes de araçazeiro Ya-Cy.

\section{Metodologia}

O experimento foi realizado na Universidade Tecnológica Federal do Paraná -Câmpus Dois Vizinhos. Frutos fisiologicamente maturos foram colhidos de 28 matrizes de araçazeiro amarelo Ya-Cy, oriundos de pomar experimental da referida instituição.

Os frutos após coletados foram levados ao Laboratório de Fisiologia Vegetal e submetidos ao despolpamento manual. Posteriormente, fez-se a extração das sementes manualmente, com auxílio de peneira e água corrente. As sementes extraídas foram deixadas para secar em ambiente aberto e sombreado por 24 horas.

$\mathrm{O}$ delineamento experimental utilizado foi inteiramente casualizado, no fatorial $2 \times 3$ (tipo de hormônio $\mathrm{x}$ concentração hormonal), com 4 repetições utilizando-se 100 sementes por unidade experimental. $\mathrm{O}$ fator hormônio envolveu o uso de 6-benzilaminopurina (BAP) e ácido giberélico (GA3), testando-os nas concentrações de 0,50 e $100 \mathrm{mg} \mathrm{L}^{-1}$. As sementes foram mantidas em cada solução hormonal por 24 horas. Foi adotado outro tratamento comumente recomendado com sementes armazenadas em geladeira por período de 20 dias, sendo em seguida lavadas com água destilada e deionizada (Silva, 2009), para então semeá-las.

As sementes foram colocadas para germinar sobre papel Germtest ${ }^{\circledR}$ mantidas no interior de caixas acrílicas do tipo Gerbox ${ }^{\circledR}$, cujas dimensões foram de $11 \times 11 \times 3,5 \mathrm{~cm}$, com uso de tampa. As caixas foram acondicionadas em câmara de incubação tipo B.O.D. com temperatura controlada entre $25 \pm 5{ }^{\circ} \mathrm{C}$ e fotoperíodo de 12 horas.

As sementes foram umedecidas diariamente por meio de adição de água no papel Germtest ${ }^{\circ}$ no interior das caixas gerbox, até o final das avaliações. A contagem das sementes germinadas foi efetuada diariamente após o início da germinação, que ocorreu 17 dias após a instalação do experimento. Foram consideradas sementes germinadas aquelas que apresentavam protrusão da radícula capaz de formar plântula normal (Brasil, 2009).

Foram avaliados a porcentagem de germinação, o tempo médio de germinação e o índice da velocidade de germinação, sendo para esta última utilizada a equação proposta por Maguire (1962). Com os dados obtidos, realizou-se o teste de normalidade de Lilliefors, no qual demonstrou-se a necessidade de transformação. Posteriormente, os dados foram submetidos as análises de variância e de regressão. Os dados referentes ao tratamento testemunha foram comparados pelo teste t com o melhor tratamento encontrado pela aplicação dos fitormônios. Para tanto fez-se uso dos programas estatísticos Genes (Cruz, 2013) e SANEST (Zonta \& Machado, 1985), para o teste de normalidade e, análise de variância, teste de comparação de médias e regressão, respectivamente.

\section{Resultados e Discussão}

Os resultados obtidos demonstraram interação tipo de hormônio $\mathrm{x}$ concentração hormonal significativa estatisticamente para porcentagem de germinação (Figura 1), IVE (Figura 2) e tempo médio de germinação (Figura 3). 
O tratamento com exposição a $50 \mathrm{mg} \mathrm{L}^{-1}$ de ácido giberélico obteve resultados estatisticamente iguais ao da testemunha em porcentagem e tempo médio de germinação, atingindo-se 75\% e 25,48 dias (Figuras 1 e 2 respectivamente).

Figura 1. Germinação de sementes de araçazeiro amarelo de acordo com o tipo de concentração de giberelina e de benzilaminopurina (BAP).

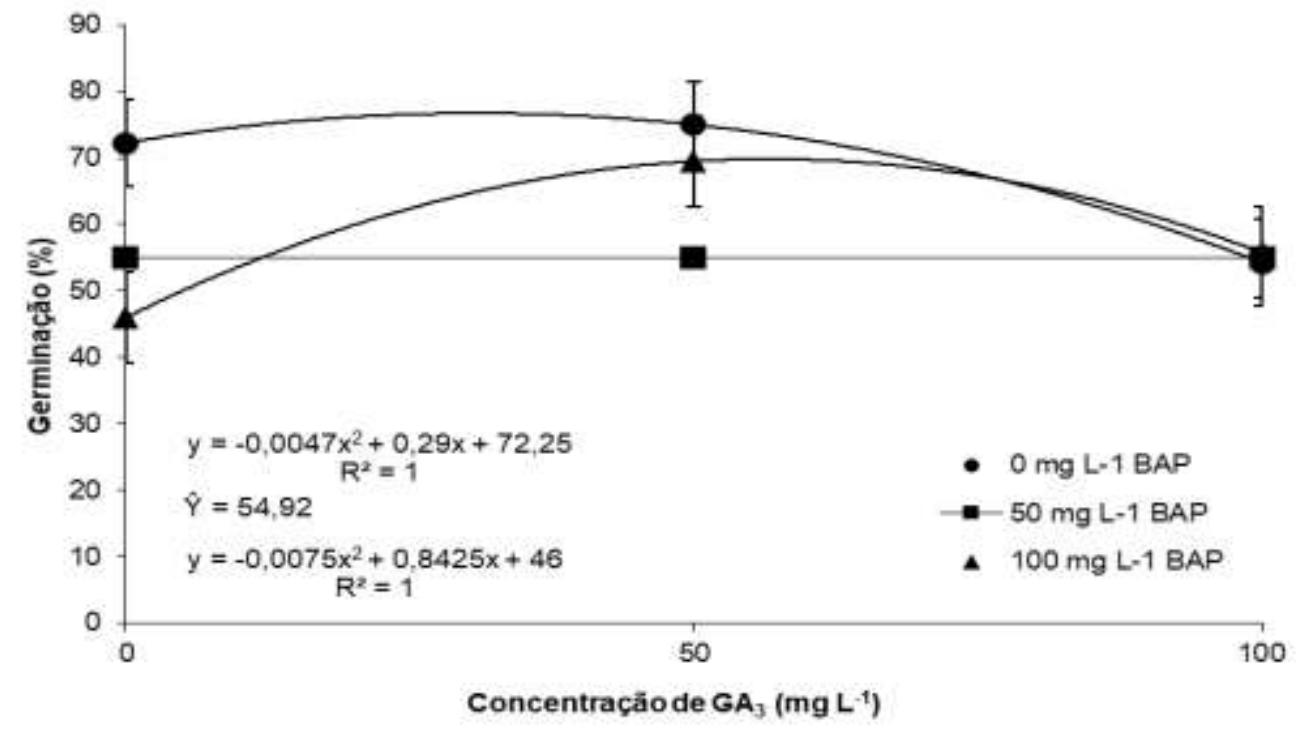

Fonte: Autores.

Figura 2. Índice de velocidade de germinação de sementes de araçazeiro amarelo de acordo com o tipo de concentração de giberelina e de benzilaminopurina (BAP).

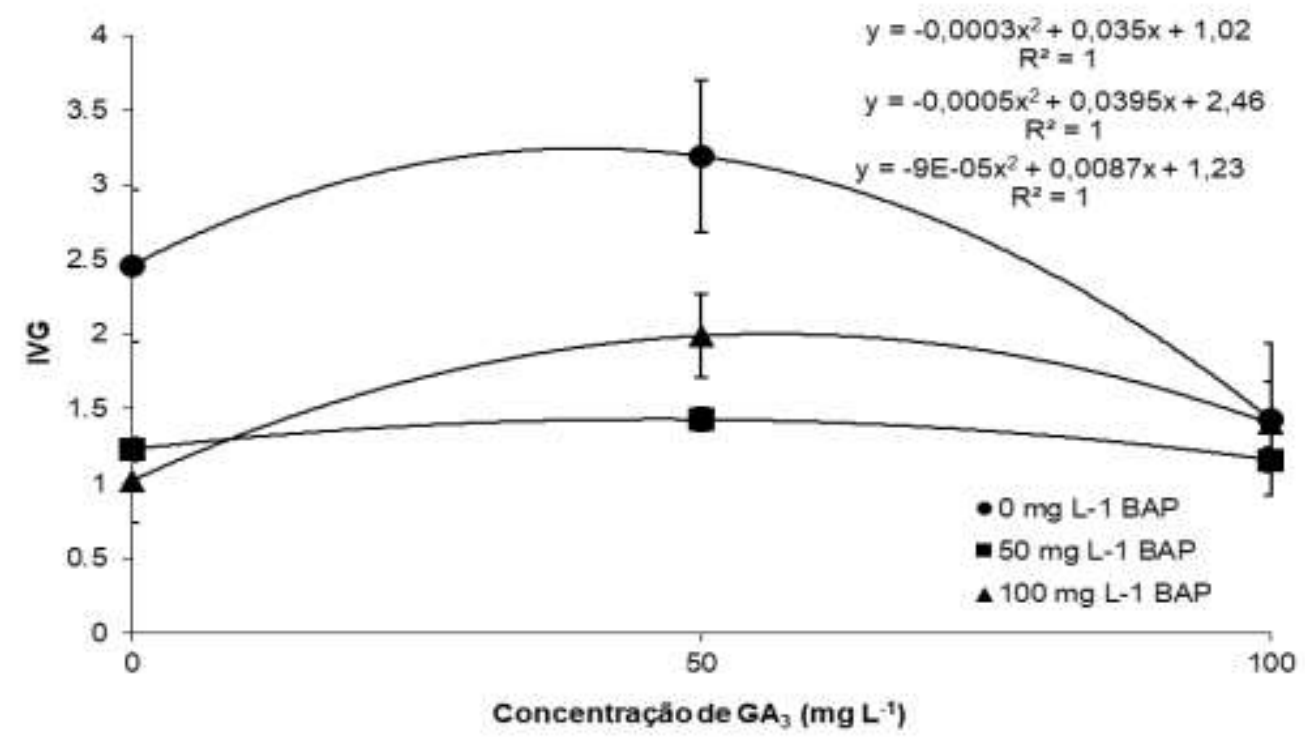

Fonte: Autores.

Quanto ao IVG, o resultado apresentou diferença estatística, sendo este tratamento superior, cujo valor foi de 2,05 (Figura 2). Com isso, comprovou-se haver dormência fisiológica nas sementes de araçazeiro amarelo, sendo esta causada pela deficiência de giberelinas.

As sementes iniciaram o processo germinativo 17 dias após a implantação do experimento, seguindo-se até os 91 dias. 
Estes resultados se assemelharam aos encontrados por Zamith \& Scarano (2004), que registraram o início da germinação de araçazeiro amarelo também aos 17 dias.

De maneira geral, a aplicação da giberelina concentração $50 \mathrm{mg} \mathrm{L}^{-1}$ reduziu significativamente a porcentagem, tempo médio e o índice de velocidade de germinação, indicando a existência de alteração hormonal que estaria impedindo ou atrasando a germinação nesta fruteira, podendo indicar a presença de dormência fisiológica nestas sementes. Tal fato concordou com Medeiros (2001), que mencionou a germinação como consequência de reações programadas e que ocorrem de maneira controlada por fitormônios. Com isso, qualquer alteração no equilíbrio destes reguladores pode interferir em processos vitais de forma a inibir ou não em algum processo envolvido na germinação.

A germinação das sementes de araçazeiro amarelo (Figura 1), indicaram padrão diferenciado em relação aos fitormônios aplicados. A adição da citocinina BAP apresentou efeito tóxico a partir das $50 \mathrm{mg} \mathrm{L^{-1 }}$ de $\mathrm{GA}_{3}$ pois o comportamento germinativo reduziu com exceção para a concentração de $50 \mathrm{mg} \mathrm{L}^{-1}$ de BAP que não apresentou diferenças entre as concentrações testadas. Quando utilizado $100 \mathrm{mg} \mathrm{L}^{-1} \mathrm{de} \mathrm{GA}_{3}$, este fitormônio parece impedir a ação do BAP, já que não registrou diferenças significativas entre as três concentrações aplicadas (Figura 1).

As citocininas são classe de fitomônios que tem função geralmente relacionada aos processos de citocinese e expansão celular, ou seja, adquirem importância como fatores da divisão e multiplicação dos tecidos (Marcos Filho, 2005). Nas sementes seus efeitos são relatados como forma de barreira à ação de inibidores, permitindo que outros fitormônios, especialmente da classe de giberelinas, possam agir de maneira a induzir a germinação (Popinigis, 1985). Acredita-se que nas sementes de araçazeiro amarelo o problema relacionado ao atraso nos processos germinativos seja pelo fato da mesma não ter sintetizado níveis de giberelina favoráveis a retomada do crescimento do embrião e não pela presença de inibidores, fato comprovado pela ausência de resultados com BAP.

Conforme exposto na Figura 1, o GA 3 apresentou ação promotora para germinação até atingir pontos de máximo nas concentrações de 30,85; 22,5 e 56,17 $\mathrm{mg} \mathrm{L}^{-1}$ com as concentrações fixas de 0,50 e $100 \mathrm{mg} \mathrm{L}^{-1}$ de BAP respectivamente. Acima destes valores este fitormônio passou a ter efeito tóxico para semente reduzindo significativamente a germinação.

Em diversos estudos referentes a aplicação exógena de fitormônios em sementes, pode-se observar que estes agem de maneira única referente à espécie e às condições do teste de germinação. Em sementes de Byrsonima crassifolia a aplicação de $500 \mathrm{mg} \mathrm{L}^{-1}$ foi capaz de quebrar a dormência da espécie (Carvalho e Nascimento, 2008). Resultado semelhante foi encontrado em Cattleya warnerii que teve a germinação estimulada conforme a quantidade de giberelinas aplicadas, sendo progressiva a 5 , 10 e $20 \mathrm{mg} \mathrm{L}^{-1}$ (Leite \& Hebling, 2007) e em Didymopanax morototoni (caixeta) que também apresentou valores de germinação progressivamente maiores à aplicação de cinetina a 0,$1 ; 0,5$ e 1,0 $\mathrm{mg} \mathrm{L}^{-1}$ (Franco e Ferreira, 2002).

Contudo, na família Myrtaceae resultados mais divergentes foram encontrados, na espécie Acca sellowiana (goiabeira serrana) com a aplicação de 0,500 e $1000 \mathrm{mg} \mathrm{L}^{-1}$ de ácido giberélico, pois este não apresentou diferenças significativas na germinação de suas sementes (Borges et al., 2008). Este mesmo fitormônio aplicado em sementes de Eugenia uvaia foram eficientes na germinação quando ainda os frutos estavam imaturos. Contudo, apresentaram complexo comportamento quando aplicados após diferentes tempos e modos de armazenamento (Scalon et al., 2004).

Quanto a velocidade de germinação das sementes (Figura 2), foi observado atraso e impedimento na germinação. Observou-se que nas concentrações de $50 \mathrm{mg} \mathrm{L}^{-1}$ de BAP e $100 \mathrm{mg} \mathrm{L}^{-1}$ de $\mathrm{GA}_{3}$ os respectivos fitormônios geraram maiores respostas para o IVG.

A aplicação de citocininas gerou efeito tóxico até as concentrações de 86,67 e 72,49 $\mathrm{mg} \mathrm{L}^{-1}$ para o IVG e TMG respectivamente (Figuras 2 e 3) quando analisado na concentração de $0 \mathrm{mg} \mathrm{L}^{-1}$ de $\mathrm{GA}_{3}$. Para concentração de $50 \mathrm{mg} \mathrm{L}^{-1}$, a curva gerada mostrou comportamento semelhante, atingindo os pontos mínimos em 82 e 66,68 mg L-1 de BAP nas mesmas variáveis citadas. Depois destas concentrações mencionadas, o fitormônio promoveu a germinação, contudo, sem atingir 
valores estatisticamente iguais aos iniciais de $0 \mathrm{mg} \mathrm{L}^{-1}$.

Figura 3. Tempo médio de germinação de sementes de araçazeiro amarelo de acordo com a concentração de giberelina e de benzilaminopurina (BAP).

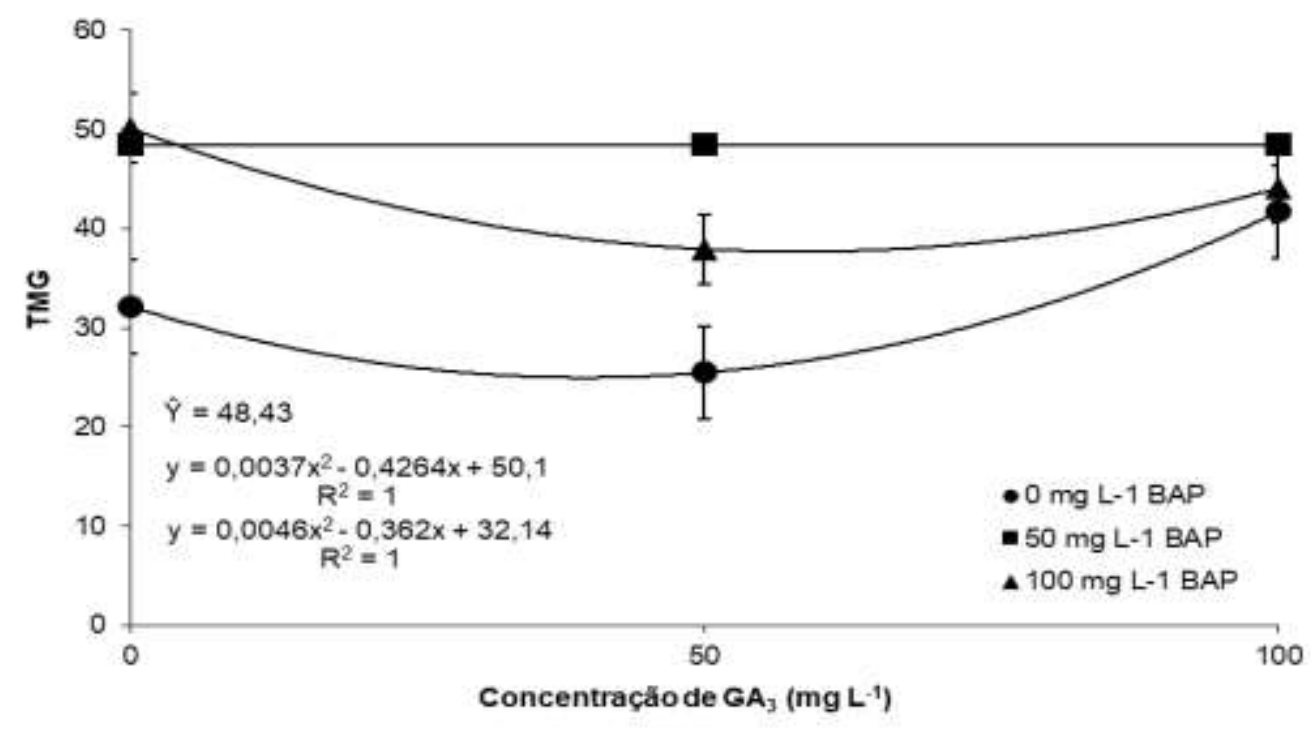

Fonte: Autores.

Na Figura 3, observou-se que a aplicação de giberelinas apresentou padrão oposto ao das citocininas. Inicialmente o fitormônio agiu de maneira a aumentar a velocidade de germinação para na sequência agir com efeito tóxico. Com $0 \mathrm{mg} \mathrm{L}^{-1}$ de BAP o ponto de máxima velocidade foi com 53 e $39,35 \mathrm{mg} \mathrm{L}^{-1}$ de $\mathrm{GA}^{3}$ para IVG e TMG, respectivamente (Figuras 2 e 3). A aplicação dos fitormônios apresentaram os melhores resultados nestas concentrações levando-se o índice de velocidade a 2,14 e o tempo médio de germinação a 25,01 dias. O máximo de IVG ocorreu a 55,5 $\mathrm{mg} \mathrm{L}^{-1}$ e o mínimo de TMG a 57,62 $\mathrm{mg} \mathrm{L}^{-1}$ de GA3 aplicado (Figuras 2 e 3, respectivamente).

No tratamento testemunha os resultados não apresentaram diferenças significativas ao comparar com o melhor tratamento com uso fitormônios (GA3 e BAP), ou seja, ao utilizar solução com $50 \mathrm{mg} \mathrm{L}^{-1}$ de GA3. Tal fato pode ser justificado pois o resfriamento de $5{ }^{\circ} \mathrm{C}$ a $10{ }^{\circ} \mathrm{C}$ pode ser meio de ativar a síntese de enzimas hidrolíticas e agir modificando o balanço hormonal existente (Marcos Filho, 2005). Tanto a aplicação de frio quanto de luz são métodos citados por Popinigis (1985) como meios capazes de induzir a síntese de giberelinas nas sementes, substituindo-os a aplicação exógena destes por meio de soluções artificiais. Aliado ao fato de o resfriamento ter induzido ao comportamento igual à aplicação de ácido giberélico, pode-se comprovar a existência de inibidores e sem determinada concentração de giberelina que estimula a geminação nas sementes. Com isso, pode-se afirmar que há pequena deficiência de giberelinas ativas pode induzir à dormência fisiológica nas sementes desta espécie.

\section{Conclusão}

Para o araçá amarelo Ya-cy não é necessário o uso de benzilaminopurina para alterar os processos germinativos. Recomenda-se o uso de $50 \mathrm{mg} \mathrm{L}^{-1}$ de giberelinas ou estratificação a frio para obter melhores respostas germinativas. 
Research, Society and Development, v. 10, n. 5, e49110515124, 2021

(CC BY 4.0) | ISSN 2525-3409 | DOI: http://dx.doi.org/10.33448/rsd-v10i5.15124

\section{Referências}

Brasil (2009). Regras para Análise de Sementes. Mapa/ACS.

Carvalho, J. E. U. \& Nascimento, W. M. O. (2008). Caracterização dos pirênios e métodos para acelerar a germinação de sementes de murici do clone Açu. Revista Brasileiras de Fruticultura. 30(3), 775-81.

Cruz, C. D. (2013). Programa GENES: Biometria. Viçosa: UFV, 382p.

Fetter, M. R., Vizzotto, M., Corbelini, B. B. \& Gonzalez, T. N. (2010). Propriedades funcionais de araçá-amarelo, araçá-vermelho (Psidium cattleyanum Sabine) e araçá-pera (P. acutangulum D.C.) cultivados em Pelotas/RS. Brasilian Journal of Food Technology. 13(15), 92-5.

Fowler, J. A. P. \& Bianchetti, A. (2000). Dormência em Sementes Florestais, Colombo: Embrapa Florestal.

Franco, E. T. H. \& Ferreira, A. G. (2002). Tratamento pré-germinativos em sementes de Didymopanax morototoni (Aubl.) Dcne. Et Planch. Ciência Florestal. 12(1), 1-10

Franzon, R. C.; Campos, L. Z. O.; Proença, C. E. B. \& Souza-Silva, J. C. (2009). Araçás do gênero Psidium: principais espécies, ocorrência, descrição e usos. Planaltina: Embrapa, 48p.

Giacobbo, C. L.; Zanuzo, M.; Chim, J.; Fachinello, J. C. (2008). Avaliação do teor de vitamina c em diferentes grupos de araçá-comum. Revista Brasileira de Agrociência. 14(1), 155-159.

Khan, A. A. (1994). Induction of dormancy in nondormant seeds. Journal of American Society for Horticultural Science. 119(3), 408-413.

Leite V. C. A. \& Hebling S. (2007). A. Efeito do ácido giberélico $\left(\mathrm{GA}_{3}\right)$ e da luz na germinação in vitro de sementes de Cattleya warnerii T. Moore. Natureza Online. 5, 55-62.

Lorenzi, H. 2008. Árvores Brasileiras: manual de identificação e cultivo de plantas arbóreas nativas do Brasil. 5 ed. Nova Odessa, SP: Instituto Plantarum, 2008 .

Lorenzi, H., Bacher, L. B., Lacerda, M. T. C. \& Sartori, S. F. (2006). Frutas brasileiras e exóticas cultivadas. Plantarum, 640p.

Maguire, J. D. (1962). Speed of germination-aid and in selection and evaluation for emergence and vigor. Crop Science. 2(1), $176-177$.

Manica, I. (2000). Frutas nativas, silvestres e exóticas. Porto Alegre: Cinco Continentes. 327p.

Marcos Filho, J. (2005). Fisiologia de sementes de plantas cultivadas. Piracicaba: Fealq.

Marques, M. C. M. \& Oliveira, P. E. A. M. (2004). Fenologia de espécies do dossel e do sub-bosque de duas Florestas de Restinga na Ilha do Mel, sul do Brasil. Revista Brasileira de Botânica. 27(4), 713-723.

Medeiros, D. (2001). Efeitos da palha de cana-de-açúcar (Saccharum spp.) sobre o manejo de plantas daninhas e dinâmica do banco de sementes. Piracicaba Escola Superior de Agricultura "Luiz de Queiroz. Dissertação de Mestrado.

Medina, A. L. (2009). Atividade antioxidante e antimicrobiana de extratos de araçá (Psidium cattleianum).). Pelotas: Universidade Federal de Pelotas. Dissertação de Mestrado.

Nachtigal, J. C. \& Fachinello, J. C. (1995). Efeito de substratos e do ácido indolbutírico no enraizamento de estacas de araçazeiro (Psidium cattleyanum Sabine). Revista Brasileira de Agrociência. 1(1), 34-39.

Popinigis, F. (1985). Fisiologia da Semente. Brasília, ABEAS, 289p.

Santos, M. S.; Petkowicz, C. L. O.; Netto, A. B. P.; Wosiacki, G.; Nogueira, A. \& Carneiro, E. B. B. 2007. Propriedade reológicas de doce em massa de araçá vermelho (Psidium cattleyanum Sabine). Revista Brasileira de Tecnologia Agroindustrial. 1(2), 104-116.

Scalon, S. P. Q.; Scalon Filho, H. \& Rigoni, M. R. (2004). Armazenamento e germinação de sementes de uvaia (Eugenia uvalha Cambess). Ciência e Agrotecnologia. 28(6), 1228-1234.

Silva, A. (2009). Morfologia, concervação e ecofisiologia da germinação de sementes de Psidium cattleianum Sabine. Tese (Doutorado), Universidade Federal de São Carlos, São Carlos.

Taiz, L.; Zeiger, E.; Moller, I. \& Murphy, A. (2017). Fisiologia e desenvolvimento vegetal. Porto Alegre: Artmed, 888p.

Trevisan, R.; Antunes, L. E. C. \& Gonçalves, E. D. (2004). Espécies frutíferas nativas do Sul do Brasil. Pelotas: Embrapa Clima Temperado, 124p.

Zamith, L. R. \& Scarano, F. R. 2004. Produção de mudas de espécies das Restingas do município do Rio de Janeiro, RJ, Brasil. Acta Botânica Brasilica. 1(18), 161-176.

Zanela, J. Wagner Júnior, A.; Cassol, D. A.; Alegretti, A. L.; Pirola. K. \& Mazaro, S. M. (2012). Biofilmes e pré-embebição de sementes na germinação. Revista Brasileira de Agrociência. 18(2-4), 229-232.

Zonta, E. \& Machado, A. A. (1985). SANEST - Sistema de análise estatística para microcomputadores. Pelotas: UFPel. 75 p. 